\title{
Community Stroke Rehabilitation Teams: Providing Home-Based Stroke Rehabilitation in Ontario, Canada
}

\author{
L. Allen, M. Richardson, A. McIntyre, S. Janzen, M. Meyer, D. Ure, D. Willems, \\ R. Teasell
}

\begin{abstract}
Background: Community stroke rehabilitation teams (CSRTs) provide a community-based, interdisciplinary approach to stroke rehabilitation. Our objective was to assess the effectiveness of these teams with respect to client outcomes. Methods: Functional, psychosocial, and caregiver outcome data. were available at intake, discharge from the program, and six-month follow-up. Repeated measures analysis of covariance was performed to assess patient changes between time points for each outcome measure. Results: A total of 794 clients met the inclusion criteria for analysis (54.4\% male, mean age $68.5 \pm 13.0$ years). Significant changes were found between intake and discharge on the Hospital Anxiety and Depression Scale total score $(p=0.017)$, Hospital Anxiety and Depression Scale Anxiety subscale ( $\mathrm{p}<0.001)$, Functional Independence Measure $(\mathrm{p}<0.001)$, Reintegration to Normal Living Index $(\mathrm{p}=0.01)$, Bakas Caregiver Outcomes Scale $(\mathrm{p}<0.001)$, and Caregiver Assistance and Confidence Scale assistance subscale $(\mathrm{p}=0.005)$. Significant gains were observed on the strength, communication, activities of daily living, social participation, memory, and physical domains of the Stroke Impact Scale (all p <0.001). These improvements were maintained at the 6-month follow-up. No significant improvements were observed upon discharge on the memory and thinking domain of the Stroke Impact Scale; however, there was a significant improvement between admission and follow-up $(\mathrm{p}=0.002)$. All significant improvements were maintained at the 6-month follow-up. Conclusions: Results indicate that the community stroke rehabilitation teams were effective at improving the functional and psychosocial recovery of patients after stroke. Importantly, these gains were maintained at 6 months postdischarge from the program. A home-based, stroke-specific multidisciplinary rehabilitation program should be considered when accessibility to outpatient services is limited.
\end{abstract}

RÉSUMÉ: Équipes communautaires de réadaptation post AVC : Apport d'une réadaptation post AVC à domicile en Ontario (Canada) Contexte: Les équipes communautaires de réadaptation post AVC (CSRT) fournissent une approche interdisciplinaire ancrée dans la communauté pour la réadaptation après un AVC. Notre objectif était d'évaluer l'efficacité de ces équipes par rapport aux aboutissements de ses clients. Méthodes: Des données d'évolution fonctionnelle, psychosociale ainsi que l'opinion des aidants ont été disponibles au moment de la prise en charge et de la sortie du programme, ainsi qu'après un suivi de six mois. L'analyse de covariance des mesures répétées a été réalisée pour évaluer les changements du patient entre chaque échéance pour chacun des critères d'évaluation. Résultats: Un total de 794 clients répondait aux critères d'inclusion pour l'analyse (54,4\% d'hommes, âge moyen 68,5 \pm 13,0 ans). Des modifications significatives ont été constatées entre la prise en charge et le congé pour le score total de l'échelle HAD (Hospital Anxiety and Depression) de mesure de l'anxiété et de la dépression $(p=0,017)$, pour la sous-échelle d'anxiété Hospital Anxiety and Depression Scale Anxiety $(p<0,001)$, la mesure d'indépendance fonctionnelle $(\mathrm{p}<0,001)$, la mesure de réintégration dans une vie normale $(\mathrm{p}=0,01)$, l'échelle de Bakas concernant les aidants (Bakas Caregiver Outcomes Scale) $(\mathrm{p}<0,001)$ et la sous-échelle d'assistance et de confiance des aidants (Caregiver Assistance and Confidence Scale assistance subscale) $(\mathrm{p}=0,005)$. Des gains significatifs ont été observés sur la force, la communication, les activités de la vie quotidienne, la participation sociale, la mémoire et les domaines physiques sur l'échelle d'impact des AVC (Stroke Impact Scale) (pour tous les éléments, p <0,001). Ces améliorations étaient conservées au suivi à 6 mois. Aucune amélioration significative n'a été constatée au moment du congé sur la mémoire et le domaine de pensée de l'échelle d'impact des AVC; il y a eu toutefois une amélioration significative entre l'admission et le suivi $(\mathrm{p}=0,002)$. Toutes les améliorations significatives ont été conservées au suivi à 6 mois. Conclusions: Les résultats indiquent que les équipes communautaires de réadaptation post AVC ont pu améliorer efficacement la récupération fonctionnelle et psychosociale des patients après un accident vasculaire cérébral. Il est important de noter que ces gains ont été maintenus 6 mois après la sortie du programme. Un programme multidisciplinaire de réadaptation spécifique basée au domicile après AVC doit être envisagé lorsque l'accès à des services pour patients ambulatoires est limité.

Keywords: Stroke, rehabilitation, community

doi:10.1017/cjn.2014.31

Can J Neurol Sci. 2014; 41: 697-703

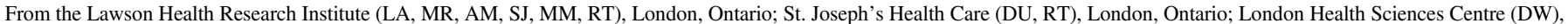
London, Ontario; Schulich School of Medicine and Dentistry (RT), Western University, London, Ontario.

Received June 4, 2014. Final Revisions Submitted September 8, 2014.

Correspondence to: Laura Allen, 550 Wellington Rd., London, Ontario, N6C 4R3 Canada. Email: laura.allen@ sjhc.london.on.ca 
Stroke is a leading cause of death and disability around the world $^{1}$ and the second leading cause of long-term disability in North America. ${ }^{2}$ It is estimated that the prevalence of stroke survivors will rise to 67 million in 2015 and 77 million by $2030 .^{3}$ Functional limitations resulting from physical and cognitive impairments after a stroke event can range from mild to severe; however, these impairments may improve over time through the use of specialized rehabilitation services. ${ }^{4}$ After acute care, stroke survivors are typically discharged to either hospital-based inpatient rehabilitation or to the community (i.e. outpatient rehabilitation, long-term care, or the home). Despite gains made in the acute phase of recovery, $33 \%$ to $43 \%$ of individuals will have residual deficits that require ongoing rehabilitation in the community. ${ }^{5}$ In recognition of this need, the 2013 Canadian Best Practice Guidelines for Stroke Care $^{6}$ state that individuals "should continue to have access to specialized stroke services after leaving the hospital" and that "[o]utpatient and/or community-based rehabilitation services should be available and provided by a specialized interprofessional team, when needed by patients [...]" (p. 33).

Outpatient rehabilitation may include hospital-based or homebased rehabilitation depending on service availability and patient need. The literature has shown that home-based rehabilitation is effective in improving clinical outcomes. ${ }^{4}$ A recent study found that, compared with a control group receiving traditional rehabilitation services, individuals receiving home-based rehabilitation showed greater improvement in independence for activities of daily living at six months (Barthel Index $p<0.05)$ and two years (Barthel Index, $\mathrm{p}=0.03$ ) poststroke. ${ }^{7}$ This finding was confirmed in a meta-analysis by Hillier et al. $^{8}$ who noted that significant improvements six months poststroke were likely from direct transference of skills to the living environment. A meta-analysis of randomized controlled trials comparing home-based and center-based stroke rehabilitation found that home-based services were associated with greater client satisfaction, reduced caregiver strain, and lower hospital readmission rates. ${ }^{9}$ In addition to the number of positive clinical outcomes associated with home-based rehabilitation, it has also been shown that these services are cost effective. In a systematic review by Anderson et al., ${ }^{10}$ home-based rehabilitation was shown to reduce hospital stays by 13 days $(95 \%$ confidence interval: -19 to -7 days). In combination with early supported discharge, community-based rehabilitation had an overall mean cost reduction of $15 \%$ compared with standard care without compromising patient outcomes. ${ }^{10}$

In southwestern Ontario, Canada, community stroke rehabilitation teams (CSRTs) provide an individualized, home-based, stroke-specific, and multidisciplinary rehabilitation service to patients recovering from stroke. Most evidence for home-based rehabilitation has originated from the United Kingdom, Australia, and the Scandinavian countries; thus, a Canadian perspective is lacking. The objective of this study was to examine the use of CSRTs in providing home-based rehabilitation to stroke survivors living in Ontario, Canada, and to evaluate their effectiveness in improving patient and caregiver outcomes.

\section{MeTHODS}

\section{CSRT Program and Dataset}

All data were derived from a retrospective cohort of clients who received care from the CSRTs between January 1, 2009, and June 30, 2013. Serving southwestern Ontario, the CSRTs comprise physical therapists, occupational therapists, speechlanguage pathologists, social workers, registered nurses, therapeutic recreational specialists, and rehabilitation therapists. Clients served by these teams must have ongoing rehabilitation needs at any time poststroke and be both able and motivated to actively participate in rehabilitation. Individuals have all been discharged from either acute care or inpatient rehabilitation. In most cases, individuals seen by the CSRTs are unable to access hospital based outpatient rehabilitation for a variety of reasons (e.g. transportation barriers, low social support).

Client data were collected from an administrative database that was maintained directly by CSRT staff. Routine data collection occurred at three time points: intake into the program, discharge, and follow-up. The discharge time point varied depending on the client's length of service. Follow-up assessments were completed within 6 months of discharge from the program. Demographic information was collected on intake, and psychosocial, functional, and caregiver outcomes were completed at intake, discharge, and follow-up to assess patient progress and to determine relevant rehabilitation goals. Upon completion, client demographic information and outcome assessments were forwarded to the CSRT program administrative assistant who entered all information into a centrally maintained database. Data collected up to June 2013 were included in the present analysis. This study was granted ethics approval by the Western University Research Ethics Board: London, Ontario.

\section{Inclusion Criteria}

To be included in the present analysis, a client must have received active rehabilitation and have complete demographic information. Additionally, clients must have had at least one baseline outcome assessment completed and at least one discharge or follow-up outcome assessment completed.

\section{Data Extraction}

Extracted demographic information included age, sex, postal code, marital status, and date and type of stroke. Other descriptive information was extracted such as date of client referral and referral source, date of first contact, date of first CSRT visit, and date of discharge from active service. Referral sources were divided into six distinct categories: acute, inpatient rehabilitation, outpatient rehabilitation, community (e.g. self, family/ friend, primary physician), in-home care provider (e.g. Community Care Access Center), and long-term care. For each patient, wait time (time between referral and first visit), time since stroke (date of stroke to first visit), and length of service (first visit to program discharge) was recorded. Information on the number of visits per client from each discipline was also available. Rehabilitation intensity was measured by calculating the average total number of therapy visits each individual received per week.

\section{Outcome Measures}

\section{Functional Outcomes}

Functional Independence Measure. The Functional Independence Measure (FIM) provides a measure of disability and an indication of independence in activities of daily living by assessing cognitive and motor functioning. ${ }^{11}$ The FIM consists of 18 items that are scored on a 7-point Likert scale, with higher scores 
indicating a greater level of independence $(1=$ total assistance, $7=$ total independence; total $=126$ ). This measure has demonstrated excellent reliability ${ }^{12}$ and validity ${ }^{13}$ within a stroke population.

Stroke Impact Scale. The Stroke Impact Scale (SIS) is a 64-item stroke-specific measure of function. It was developed to assess important consequences of stroke, specifically for those with mild to moderately severe stroke, and is sensitive to small changes in function. The SIS consists of eight domains: strength, hand function, instrumental activities of daily living, mobility, communication, memory, emotion and thinking, and social participation. ${ }^{14}$ This measure has excellent reliability and validity. ${ }^{15}$ The SIS was used by CSRT staff from January 2009 to October 2012, and was replaced by the Reintegration to Normal Living Index in May 2012.

Reintegration to Normal Living Index. The Reintegration to Normal Living Index indicates the extent to which an individual has returned to normal social activities after a traumatic illness. The measure consists of 11 items categorized into two domains: daily functioning and perception of self. The degree to which a statement describes the individual's situation is graded, providing a total maximum score of 22 , with a higher score indicating a greater degree of reintegration. ${ }^{16}$ This measure has demonstrated excellent internal consistency in several studies when administered to both stroke patients (alpha $=0.80-0.92)$ and their family members $($ alpha $=0.81-0.85) .{ }^{17,18}$

\section{Psychosocial Outcomes}

The Hospital Anxiety and Depression Scale. This scale consists of seven depression-related items and seven anxiety-related items. Each item is measured on a 4-point scale, resulting in a maximum score of 21 in each subscale and an overall total score of $42 .{ }^{19}$ A higher score may indicate more prominent symptoms of depression and/or anxiety. This tool was administered by the CSRT staff until January 2011. Psychosocial outcomes continued to be measured using the Patient Health Questionnaire 9; however, there were insufficient data available to report.

\section{Caregiver Outcomes}

The Caregiver Assistance and Confidence Scale (CACS). The CACS is used to measure the amount of assistance a caregiver provides to a dependent individual (burden of care) as well as the level of confidence with which he or she is able to provide this assistance. This measure contains 17 items, with each item containing two subscales (level of assistance required and level of confidence in providing assistance). A maximum total score of 102 in each category can be achieved. Higher scores in the level of assistance subscale reflect a high level of assistance (burden); higher scores in the level of confidence subscale indicate a high level of confidence in providing required assistance. ${ }^{20}$ The CSRT transitioned from this tool to the Bakas caregiver outcomes scale (BCOS) in October 2011.

BCOS. The BCOS is a 15-item measure developed to examine the emotional, social, and health-related outcomes of an individual providing informal care to a person who has experienced a stroke. Individuals rate items based on a -3 to +3 scale, which affords the opportunity to reflect both the negative and positive aspects of a caregiver role. These scores are then converted to a 1 to 7 scale, resulting in a maximum total score of 105 , where a higher score reflects a more positive caregiving experience. ${ }^{21}$

\section{Analysis}

Demographic characteristics of this population were described by calculating frequencies and means where appropriate. To compare patients excluded because of incomplete data with those in the analyzed data set, paired t-tests and chi-square tests were conducted on all demographic characteristics to detect statistically significant differences between the two cohorts.

Repeated measures analysis of covariance (ANCOVA) was conducted for each outcome measure, and subscales when appropriate, to examine changes in mean total score between time points (admission, discharge, and follow-up). This method of analysis was chosen as it is suited to pre-post data with more than two time points while controlling for potential confounding variables. All outcome variables were continuous, approximately normally distributed, and had significant outliers removed at all three time points. The sphericity assumption was tested with each model using Mauchly's Test of Sphericity with a GreenhouseGeisser correction when required. This was completed to assess the type 1 error rate of each model. Pairwise comparisons of the three time points with each ANCOVA model were examined to assess significant differences in mean client outcome scores across the time points with a Bonferroni correction $(\mathrm{p}<0.017)$. This analysis was repeated to examine caregiver outcomes. Known confounders to the stroke recovery process (age, ${ }^{22}$ intensity of services, ${ }^{23}$ and admission FIM score ${ }^{22}$ ) were controlled for as covariates within each model. All analyses were completed using SPSS v.21.0.

\section{Results}

The analysis included 794 clients for which complete demographic and outcome measure data were available. The demographic characteristics of the cohort are presented in Table 1. Overall, the majority of clients were older ( $>65$ years) and had an average admission FIM score of 105, indicating good motor and cognitive functioning. Almost $50 \%$ of clients were referred from inpatient rehabilitation. Program-related characteristics are presented in Table 2. On average, clients received approximately two visits per week and stayed in the program for four months. A comparison of demographics for the analyzed cohort and cohort of excluded individuals revealed no statistically significant difference between the two populations on any characteristic, with the exception of mean length of stay in the program for which the analyzed cohort had a significantly longer length of stay in the program (mean 113.4 vs. 125.2 days; $p=0.003$ )

The sphericity assumption was met in all models. Results of the repeated measures ANCOVA of client and caregiver outcomes are presented in Table 3. There were no significant improvements in the Memory and Thinking subscale of SIS between admission and discharge; however, a statistically significant improvement in score was found between admission and follow-up ( -8.43 to $-1.47, \mathrm{p}=0.002)$ The Depression subscale of the SIS trended toward significance $(p=0.017)$ from admission to discharge from the program, and all other pairwise comparisons for each client outcome and subdomain scores improved significantly between admission to the program and discharge from services (all $\mathrm{p}<0.017$ ). All of these improvements were maintained at the 6-month follow-up (all $\mathrm{p}>0.017$ ). Analysis could not be completed on the Psychosocial domain of the SIS because 3 items in this domain were not coded correctly when entered 


\section{Table 1: Demographic characteristics}

\begin{tabular}{|c|c|}
\hline Characteristics & Mean (SD) \\
\hline Sample size & 794 \\
\hline Age & $68.5(13.0)$ \\
\hline Baseline FIM & $106.1(17.3)$ \\
\hline Time poststroke (weeks) & $21.3(49.7)$ \\
\hline Wait time (days) & $9.0(18.3)$ \\
\hline \multicolumn{2}{|l|}{ Gender, N (\%) } \\
\hline Male & $432(54.4)$ \\
\hline Female & $362(45.6)$ \\
\hline \multicolumn{2}{|l|}{ Marital status, N (\%) } \\
\hline Single & $55(7.6)$ \\
\hline Married & $457(62.8)$ \\
\hline Common law & $45(6.2)$ \\
\hline Divorced & $31(4.3)$ \\
\hline Widowed & $127(17.4)$ \\
\hline Separated & $13(1.8)$ \\
\hline \multicolumn{2}{|l|}{ Referral source, N (\%) } \\
\hline Acute & $183(23.0)$ \\
\hline Inpatient rehabilitation & $394(49.6)$ \\
\hline Outpatient rehabilitation & $29(3.7)$ \\
\hline Community & $76(9.6)$ \\
\hline CCAC & $111(14.0)$ \\
\hline Long-term care & $1(0.1)$ \\
\hline \multicolumn{2}{|l|}{ Stroke type, N (\%) } \\
\hline Ischemic & $578(80.3)$ \\
\hline Hemorrhagic & $123(17.1)$ \\
\hline TIA/unknown & $9(2.6)$ \\
\hline
\end{tabular}

$\mathrm{SD}=$ standard deviation; $\mathrm{FIM}=$ functional independence measure;

$\mathrm{CCAC}=$ community care access center; TIA $=$ transient ischemic attack.

into the dataset, and data were only available at an aggregate score level. The CACS level of assistance subscale scores significantly improved between admission and follow-up time points $(\mathrm{p}<0.017)$, with gains maintained between discharge and follow-up. These results were also observed with the BCOS. No significant gains were observed between any time points on the CACS level of confidence subscale.

\section{Discussion}

Our objective was to describe the provision of services by an existing home-based, multidisciplinary rehabilitation program and the impact of those services on patient and caregiver outcomes poststroke. Using a retrospective cohort of clients who received CSRT services in southwestern Ontario, Canada, between 2009 and 2013, we found that clients remained in the program for an average of 125 days and received a mean of 34 visits. Clients experienced statistically significant improvements in functional and psychosocial outcomes and had a greater sense of reintegration into daily activities after being discharged from
Table 2: Program characteristics

\begin{tabular}{l|c}
\hline Program characteristic & Mean (SD) \\
\hline Sample size & 794 \\
\hline Number of visits & \\
\hline Physiotherapist & $5.0(7.0)$ \\
\hline Occupational therapist & $5.2(5.7)$ \\
\hline Speech-language pathologist & $3.1(5.5)$ \\
\hline Therapeutic recreation specialist & $3.5(4.9)$ \\
\hline Rehabilitation therapist & $10.3(11.8)$ \\
\hline Registered nurse & $4.4(3.7)$ \\
\hline Social worker & $2.1(3.3)$ \\
\hline Total & $33.6(26.3)$ \\
\hline Length of stay (days) & $125.2(83.9)$ \\
\hline Intensity (visits/week) & $2.3(1.7)$ \\
\hline
\end{tabular}

$\mathrm{SD}=$ standard deviation

the program. Gains made by the clients during active rehabilitation were maintained at follow-up.

The functional and psychosocial improvements shown in this cohort are comparable to those made in other studies assessing the effectiveness of home-based therapy. ${ }^{8,24}$ Markle-Reid and colleagues ${ }^{24}$ assessed the effectiveness of a community-based program which showed no statistically significant improvement in health-related quality of life (SF-36); however, there was a clinically significant improvement in scores during the study period. To overcome the challenges of interpreting data with no control group, we were similarly able to compare our findings according to clinically meaningful changes. Lin et al. ${ }^{25}$ identified clinically meaningful changes in scores for patients in the chronic stage of stroke for several domains of the SIS. Based on those authors' criteria, the patients in this study had clinically important improvements in strength $(\Delta=11)$, activities of daily living $(\Delta=7)$, and mobility $(\Delta=10)$. Furthermore, the change in FIM score experienced by our population can offer additional information. Granger et al. ${ }^{26}$ found that for every 1-point increase in total FIM score, the amount of assistance needed by a patient with a stroke decreased by 2.19 minutes. Therefore, the 5-point change in score observed in this study could equate to a savings of more than ten minutes in daily care provisions. This is supported by our finding of a decrease in level of caregiver assistance required between intake and discharge from the CSRT program. Given that deterioration of gains after stroke rehabilitation is possible, ${ }^{27,28}$ the maintenance of gains at follow-up in our study suggest that continued rehabilitation in the community is beneficial over the long term. Future studies should assess the impact of CSRTs on client outcomes beyond the 6-month follow-up period assessed in the present study.

The effectiveness of organized stroke-specific rehabilitation services for acute and inpatient settings is well-known. Less wellknown is what model of care is best suited for patients who require continued rehabilitation in the community. Limited studies have been identified that examine multidisciplinary rehabilitation interventions. ${ }^{29}$ Most often, the community-based programs were limited to stand-alone rehabilitation therapies such as physiotherapy, ${ }^{30}$ 
Table 3: Results of repeated measures ANCOVA

\begin{tabular}{|c|c|c|c|c|c|c|}
\hline \multirow[t]{2}{*}{ Measure } & \multirow[t]{2}{*}{ Sample size } & \multicolumn{3}{|c|}{ Mean (SD) } & \multirow{2}{*}{$\begin{array}{l}\text { p value }(95 \% \mathrm{CI}) \\
\text { intake to discharge }\end{array}$} & \multirow{2}{*}{$\begin{array}{l}\text { p value }(95 \% \mathrm{CI}) \\
\text { discharge to follow-Up }\end{array}$} \\
\hline & & Intake & discharge & 6-month follow-Up & & \\
\hline FIM & 333 & $105.25(17.2)$ & $110.34(16.1)$ & $110.54(16.1)$ & $<0.001(-6.3$ to -3.9$)$ & $1.000(-1.0$ to 0.7$)$ \\
\hline RNLI & 55 & $15.69(4.7)$ & $17.6(3.7)$ & $18.20(4.1)$ & $0.010(-3.4$ to -0.4$)$ & $0.653(-2.0$ to 0.7$)$ \\
\hline \multicolumn{7}{|l|}{ SIS } \\
\hline Strength & 140 & $56.12(26.0)$ & $67.10(24.8)$ & $64.33(26.4)$ & $<0.001(-15.5$ to -6.5$)$ & $0.264(-1.1$ to 6.7$)$ \\
\hline Memory & 140 & $75.03(19.7)$ & $77.63(20.1)$ & $79.97(17.7)$ & $0.289(-6.4$ to 1.2$)$ & $0.303(-5.8$ to 1.1$)$ \\
\hline Communication & 140 & $76.17(22.4)$ & $80.59(21.2)$ & $82.04(18.2)$ & $0.014(-8.1$ to -0.7$)$ & $0.660(-4.3$ to 1.4$)$ \\
\hline ADL & 140 & $66.75(21.8)$ & $74.0(22.0)$ & $75.59(22.7)$ & $<0.001(-10.7$ to -3.8$)$ & $0.775(-4.9$ to 1.8$)$ \\
\hline Mobility & 140 & $63.02(24.4)$ & $73.29(22.3)$ & $73.77(22.8)$ & $<0.001(-13.6$ to -6.9$)$ & $1.000(-3.7$ to 2.7$)$ \\
\hline Hand strength & 140 & $49.46(36.4)$ & $61.21(36.0)$ & $60.79(37.0)$ & $<0.001(-16.7$ to -6.8$)$ & $1.000(-4.5$ to 5.4$)$ \\
\hline Social participation & 140 & $49.87(23.2)$ & $65.63(23.5)$ & $69.46(21.4)$ & $<0.001(-20.7$ to -10.8$)$ & $0.198(-8.9$ to 1.2$)$ \\
\hline Physical & 140 & $60.94(21.5)$ & $70.50(21.4)$ & $70.75(21.7)$ & $<0.001(-12.0$ to -7.1$)$ & $1.000(-2.6$ to 2.1$)$ \\
\hline \multicolumn{7}{|l|}{ HADS } \\
\hline Anxiety & 86 & $7.03(4.3)$ & $5.55(3.9)$ & $5.30(3.7)$ & $<0.001(0.6$ to 2.4$)$ & $1.000(-0.5$ to 1.0$)$ \\
\hline Depression & 86 & $6.45(3.9)$ & $5.45(3.5)$ & $5.02(3.3)$ & 0.017 (0.1 to 1.9$)$ & $0.555(-0.4$ to 1.2$)$ \\
\hline Total & 86 & $13.5(7.0)$ & $11.0(6.4)$ & $10.36(5.9)$ & $<0.001$ (1.0 to 4.0$)$ & $0.725(-0.7$ to 2.0$)$ \\
\hline \multicolumn{7}{|l|}{ CACS } \\
\hline Assistance & 49 & $39.96(25.9)$ & $32.10(24.6)$ & $28.82(22.0)$ & 0.005 (2.0 to 13.7$)$ & $0.146(-0.7$ to 7.3$)$ \\
\hline Confidence & 49 & $68.80(35.9)$ & $61.88(39.8)$ & $65.06(40.4)$ & $0.442(-4.7$ to 18.5$)$ & $0.965(-11.1$ to 4.7$)$ \\
\hline BCOS & 63 & $48.87(8.7)$ & $54.68(11.8)$ & $53.73(11.5)$ & $<0.001(-9.2$ to -2.4$)$ & $1.000(-2.0$ to 3.9$)$ \\
\hline
\end{tabular}

$\mathrm{SD}=$ standard deviation; $\mathrm{CI}=$ confidence interval $\mathrm{RNLI}=$ reintegration into normal living index; $\mathrm{ADL}=$ activities of daily living; $\mathrm{BCOS}=\mathrm{Bakas}$ caregiver outcomes scale.

occupational therapy, ${ }^{31}$ education, ${ }^{32}$ caregiver training, ${ }^{33}$ or a combination of two or three disciplines. ${ }^{34,35}$ The CSRT are a unique multidisciplinary program that is truly integrated and team-based. Services are not prescriptive; care plans are individualized to each patient based on their needs and goals within the home context. Care plans are discussed at team rounds and caregivers are heavily involved in goal setting. Given the evidence for patient-centered and goal-oriented therapy that is constantly changing over a patient's continuum of recovery, ${ }^{36}$ the CSRTs are guided by elements that may offer advantages over standard models of care.

Canadian Best Practice Recommendations for Stroke Care state that therapy provided in the outpatient and/or communitybased setting should involve "a minimum of 45 minutes per day (up to 3 hours per day), 3-5 days per week" (p.33), and be "based on individual patient needs and goals." 37 Likewise, the UK guidelines $^{38}$ suggest that patients receive " 45 minutes of each relevant stroke rehabilitation therapy for a minimum of 5 days per week" (p. 33). Both guidelines specify that this is applicable for patients who are able to actively participate in rehabilitation and have achievable rehabilitation goals. The CSRTs provided 2.3 client visits per week on average. This intensity is comparable to the rehabilitation intensity reported in the early-supported discharge (ESD) literature; for example, Donnelly et al. ${ }^{39}$ reported 2.5 visits per week and Bjorkdahl et al. ${ }^{40}$ reported 9 hours per week for 3 weeks. ESD services are meant to provide rehabilitation services in place of inpatient rehabilitation; therefore, this level of intensity is often not seen outside of the ESD literature.
The ideal intensity for community-based rehabilitation is unknown; however, a randomized controlled trial by Ryan et al. ${ }^{41}$ found that patients who received a higher level of rehabilitation, similar to that detected in the present study, experienced statistically significant improvements in social participation and quality of life scores. ${ }^{41}$

\section{Limitations}

This analysis used data collected for administrative purposes and, as such, contains inherent limitations and challenges. Data were collected by a number of individuals, which may lead to inconsistencies in the administration, scoring, or interpretation of the tools. However, the majority of outcomes measures are validated tools that have good inter-rater reliability. Furthermore, training on outcome measure administration was provided to all CSRT staff.

Due to high levels of missing data, as is often the case when using administrative data, the number of patients available for analysis was much lower than the number of patients who received active services. There were no significant differences in the characteristics of patients who were analyzed compared with those who were not, except for mean length of stay in the program. This suggests that the analyzed cohort is likely not a biased representation of the program population.

Finally, the CSRT program is a highly individualized program with client features and needs that vary greatly that may not have been accounted for in this analysis. In particular, length of stay in 
the program varied between patients, resulting in different time points for the follow-up assessments. An attempt to account for this was made with the inclusion of appropriate covariates. Furthermore, that this was an ongoing, "real-time" program meant that characteristics of the program itself have changed over time (e.g. target length of stay, staffing levels, outcome assessments). These specific program changes are very difficult to account for and must be considered when interpreting results of any analysis.

In addition to limitations of using administrative data and the evaluation of an ever-evolving program, this analysis did not include a control group for comparison purposes. Because of the nature of the intervention, ethical concerns preclude the opportunity to randomize patients to a control and intervention group, and the gains made by the present cohort of clients should be interpreted with this understanding.

\section{Conclusions}

Our study provides evidence for the effectiveness of a multidisciplinary, stroke-specific, home-based rehabilitation program in improving patient outcomes after stroke. CSRTs are one example of a successful community stroke rehabilitation team; however, the ideal structure that should be used to maximize patient outcomes remains unknown. ${ }^{42}$ Furthermore, the costeffectiveness of this program should be examined. Future research should attempt to uncover the "black box" of community rehabilitation services in search of the ideal content, intensity, and duration of services and to identify those patients who may benefit most.

\section{REFERENCES}

1. Jaracz K, Grabowska-Fudala B, Kozubski W. Caregiver burden after stroke: towards a structural model. Neurol Neurochir Polska. 2012;46(3):224-32.

2. Heart and Stroke Foundation. Statistics. 2013, Available from: http:// www.heartandstroke.com/site/c.ikIQLcMWJtE/b.3483991/k.34A8/ Statistics.htm.

3. Strong K, Mathers C, Bonita R. Preventing stroke: saving lives around the world. Lancet Neurol. 2007;6(2):182-7.

4. Teasell R, Foley N, Salter K, et al. Evidence based review of stroke rehabilitation. 16th ed. 2013. Available from: www. ebrsr.com.

5. Jørgensen HS, Nakayama H, Raaschou HO, Vive-Larsen J, Støier M, Olsen TS. Outcome and time course of recovery in stroke. Part II: time course of recovery. The Copenhagen Stroke Study. Arch Phys Med Rehabil.. 1995;76(5):406-12.

6. Heart and Stroke Foundation. Canadian Best Practice Guidelines for Stroke Rehabilitation: Outpatient and Community-Based Stroke Rehabilitation (Including ESD). 2013. Available from: http://www. strokebestpractices.ca/index.php/stroke-rehabilitation/outpatient-andcommunity-based-stroke-rehabilitation-including-esd/.

7. Chaiyawat P, Kulkantrakorn K. Randomized controlled trial of home rehabilitation for patients with ischemic stroke: impact upon disability and elderly depression. Psychogeriatrics. 2012;12: 193-9.

8. Hillier S, Inglis-Jassiem G. Rehabilitation for community-dwelling people with stroke: home or centre based? A systematic review. Int J Stroke. 2010;5:178-86.

9. Winkel A, Ekdahl C, Gard G. Early discharge to therapy-based rehabilitation at home in patients with stroke: a systematic review. Phys Ther Rev. 2008;13(3):167-87.

10. Anderson C, Mhurchu C, Rubenach S, Clark M, Spencer C, Winsor A. Home or hospital for stroke Rehabilitation? Results of a randomized controlled trial: II: cost minimization analysis at 6 months. Stroke. 2000;31:1032-7.
11. Keith RA, Granger CV, Hamilton BB, Sherwin FS. The functional independence measure: a new tool for rehabilitation. Adv Clin Rehabi. 1987;1:6-18.

12. Hobart J, Lamping D, Freeman J, et al. Which disability scale for neurologic rehabilitation? Neurology. 2001;57:639-44.

13. Kwon S, Hartzema AG, Duncan PW, Min-Lai S. Disability measures in stroke: relationship among the Barthel Index, the Functional Independence Measure, and the Modified Rankin Scale. Stroke. 2004:35(4):918-23.

14. Duncan PW, Bode RK, Min Lai S, Perera S. Rasch analysis of a new stroke-specific outcome scale: the Stroke Impact Scale. Arch Phys Med Rehabil. 2003;84(7):950-63.

15. Duncan P, Wallace D, Lai S, Johnson D, Embretson S, Jacobs Laster L. The stroke impact scale: evaluation of reliability, validity and sensitivity to change. Stroke. 1999;30:2131-40.

16. Wood-Dauphinee S, Williams J. Reintegration to normal living as a proxy to quality of life. J Chronic Dis. 1987;40(6):491-9.

17. Bluvol A, Ford-Gilboe M. Hope, health work and quality of life in families of stroke survivors. J Adv Nurs. 2004;48(4): 322-32.

18. Tooth LR, McKenna K, Smith M, O'Rourke PK. Reliability of scores between stroke patients and significant others on the Reintegration to Normal Living (RNL) Index. Disabil Rehabil. 2003;25(9):433-40.

19. Zigmond AS, Snaith RP. The hospital anxiety and depression scale. Acta Psychiatrica Scand. 1983;67(6):361-70.

20. Cameron JI, Franche RL, Cheung AM, Stewart DE. Lifestyle interference and emotional distress in family caregivers of advanced cancer patients. Cancer. 2002;94(2):521-7.

21. Bakas T, Champion V. Development and psychometric testing of the Bakas Caregiving Outcomes Scale. Nurs Res. 1999;48(5): 250-9.

22. Kwakkel G, Kollen BJ. Predicting activities after stroke: what is clinically relevant? Int J Stroke. 2013;8(1):25-32.

23. Kwakkel G, Wagenaar RC, Koelman TW, Lankhorst GJ, Koetsier JC. Effects of intensity of rehabilitation after stroke. A research synthesis. Stroke. 1997;28(8):1550-6.

24. Markle-Reid M, Orridge C, Weir R, et al. Interprofessional stroke rehabilitation for stroke survivors using home care. Can J Neurolog Sci. 2011;38(2):317-34.

25. Lin $\mathrm{KC}, \mathrm{Fu} \mathrm{T}, \mathrm{Wu} \mathrm{CY}$, et al. Minimal detectable change and clinically important difference of the Stroke Impact Scale in stroke patients. Neurorehabil Neural Repair. 2010;24(5): 486-92.

26. Granger CV, Cotter AC, Hamilton BB, Fiedler RC. Functional assessment scales: a study of persons after stroke. Arch Phys Med Rehabil. 1993;74(2):133-8.

27. van de Port IG, Kwakkel G, van Wijk I, Lindeman E. Susceptibility to deterioration of mobility long-term after stroke: a prospective cohort study. Stroke. 2006;37(1):167-71.

28. van Wijk I, Algra A, van de Port IG, Bevaart B, Lindeman E. Change in mobility activity in the second year after stroke in a rehabilitation population: who is at risk for decline? Arch Phys Med Rehabil. 2006;87(1):45-50.

29. Fens M, Vluggen T, van Haastregt JC, Verbunt JA, Beusmans GH, van Heugten CM. Multidisciplinary care for stroke patients living in the community: a systematic review. J Rehabil Med. 2013;45 (4):321-30

30. Nadeau SE, Wu SS, Dobkin BH, et al. Effects of task-specific and impairment-based training compared with usual care on functional walking ability after inpatient stroke rehabilitation: LEAPS Trial. Neurorehabi Neural Repair. 2013;27(4): 370-80.

31. Walker MF, Gladman JR, Lincoln NB, Siemonsma P, Whiteley T. Occupational therapy for stroke patients not admitted to hospital: a randomised controlled trial. Lancet. 1999;354(9175): 278-80.

32. Ostwald SK, Godwin KM, Cron SG, Kelley CP, Hersch G, Davis S. Home-based psychoeducational and mailed information programs for stroke-caregiving dyads post-discharge: a randomized trial. Disabil Rehabil. 2014;36(1):55-62.

33. Forster A, Dickerson J, Young J, et al. A structured training programme for caregivers of inpatients after stroke (TRACS): 
a cluster randomised controlled trial and cost-effectiveness analysis. Lancet. 2013;382(9910):2069-76.

34. Gladman JR, Lincoln NB, Barer DH. A randomised controlled trial of domiciliary and hospital-based rehabilitation for stroke patients after discharge from hospital. J Neurol, Neurosurg Psychiatry. 1993;56(9):960-6.

35. Wolfe CD, Tilling K, Rudd AG. The effectiveness of communitybased rehabilitation for stroke patients who remain at home: a pilot randomized trial. Clin Rehabil. 2000;14(6):563-9.

36. Wood JP, Connelly DM, Maly MR. 'Getting back to real living': A qualitative study of the process of community reintegration after stroke. Clin Rehabil. 2010;24(11):1045-56.

37. Dawson A, Knox J, McClure A, Foley N, Teasell R. Chapter 5 Stroke Rehabilitation, Canadian Best Practice Recommendations for Stroke Care. Ottawa, Ontario, Canada: Heart and Stroke Foundation and the Canadian Stroke Network; 2013.
38. NICE clinical guidelines. Stroke rehabilitation: long-term rehabilitation after stroke. 2013. Available from: http://publications.nice. org.uk/stroke-rehabilitation-cg162.

39. Donnelly M, Power M, Russell M, Fullerton K. Randomized controlled trial of an early discharge rehabilitation service: the Belfast Community Stroke Trial. Stroke. 2004;35(1):127-33.

40. Bjorkdahl A, Nilsson AL, Grimby G, Sunnerhagen KS. Does a short period of rehabilitation in the home setting facilitate functioning after stroke? A randomized controlled trial. Clin Rehabil. 2006;20 (12):1038-49.

41. Ryan T, Enderby P, Rigby AS. A randomized controlled trial to evaluate intensity of community-based rehabilitation provision following stroke or hip fracture in old age. Clin Rehabil. 2006;20(2):123-31.

42. Outpatient Service Trialists. Therapy-based rehabilitation services for stroke patients at home. The Cochrane Database of Systematic Reviews. 2003(1)Cd002925. 